Fevereiro de 2010.

\title{
Patrick Senécal: um homem de Drumondville
}

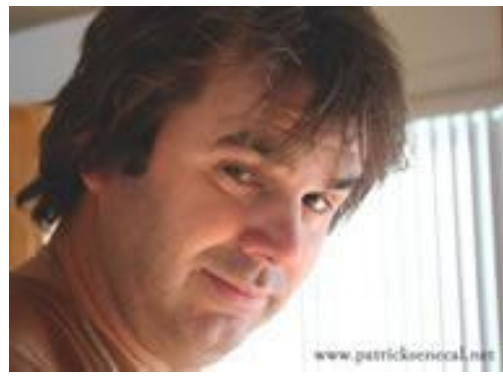

C'est à Drummondville, le 20 octobre 1967, qu'est né Patrick au sein d'une famille qui compte deux enfants. Certains écrivains affirment que le fait d'avoir eu une enfance difficile les a poussés vers l'écriture : c'est vraisemblablement tout le contraire pour

Patrick qui a eu une enfance heureuse et de bons parents. Dès l'âge de 10 ans, Patrick se laisse aller à son besoin de mettre sur papier les images créées dans sa tête. Il commence par faire un peu de bandes dessinées avec un ami plus vieux jusqu'à l'âge d'environ 13 ans. C'est à cet âge qu'il commence à écrire des nouvelles, lui qui a alors déjà une certaine fascination pour le côté sombre de l'être humain. Attiré tout d'abord par la médecine, il se rend compte, alors étudiant au CÉGEP de Drummondville, que ce n'est pas pour lui. Il préfère plutôt étudier arts et lettres. C'est pendant ces mêmes années au CÉGEP qu'il publie son premier petit roman en 50 exemplaires, «La vengeance », qui ne reflète plus l'écriture de l'auteur que Patrick est devenu. Patrick fait ensuite un BAC en études françaises à l'Université de Montréal avant de faire quelques cours de cinéma au niveau de la maîtrise.

Revista Acolhendo: - SVP, parlez-nous un peu de l'ensemble de votre oeuvre pour nos lecteurs.

Senécal: Depuis 1994, j'ai écrit huit romans pour adultes et un pour enfants. J'ai écrit aussi trois adaptations cinématographiques de mes romans. Mes histoires sont parfois policières, parfois des thrillers, parfois des histoires 
surnaturelles, mais toujours très noires, très dures, qui explorent le côté sombre de l'humain.

Revista Acolhendo:- À votre avis, pourquoi votre oeuvre a été bien reçue chez les jeunes du Québec?

Senécal: Quand on est adolescents, on aime les histoires à sensations fortes, et je crois qu'il y en a beaucoup dans mes livres. De plus, mon écriture est très cinématographique, ce qui doit plaire aux jeunes.

Revista Acolhendo: Est-ce que vous avez des plans pour sortir votre oeuvre dans d'autres pays?

Senécal: J'ai des romans traduits en polonais, en italien et en espagnol.

Revista Acolhendo: Et au Brésil ?

Senécal: Moi, je veux bien! Il faut voir avec mon éditeur! :)

Revista Acolhendo: Comment votre oeuvre pourrait être utile pour les étudiants brésiliens?

Senécal: Je ne crois pas que mes romans sont "utiles", ce sont des suspenses. Mais en tout cas, les brésiliens pourraient découvrir le Québec à travers mes romans...

\section{VEJA ALGUMAS IMAGENS DO QUEBEC...}

\section{Entrevista realizada em fevereiro de 2010.}

\section{Como citar esta entrevista:}

ACOLHENDO, Revista. Patrick Senécal: um homem de Drumondville. Revista ACOALFAplp: Acolhendo a Alfabetização nos Países de Língua portuguesa, São Paulo, ano 4, n. 8, 2010. Disponível em: <http://www.acoalfaplp.net>. Publicado em: março - setembro de 2010. 